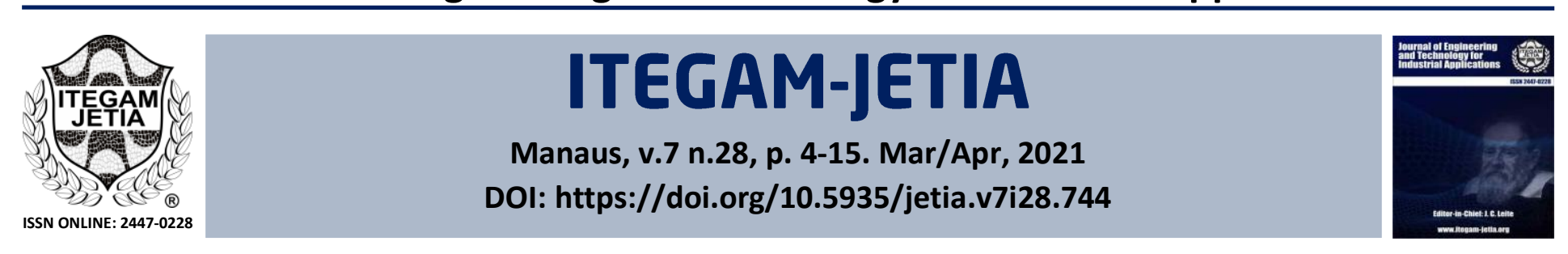

\title{
STATISTICAL ANALYSIS FOR THE FINANCIAL REPORT FROM ENERGY STREAM/REVENUE IN IRANIAN SMALL AND MEDIUM-SIZED INDUSTRIES
}

\author{
Malek Hassanpour*1 \\ ${ }^{1}$ Department of Environmental Science, UCS, Osmania University, Telangana State, India.
}

${ }^{1}$ http://orcid.org/0000-0001-9662-0623 (1)

Email: *malek.hassanpour@yahoo.com

\begin{tabular}{|c|c|}
\hline ARTICLE INFO & ABSTRACT \\
\hline $\begin{array}{l}\text { Keywords: } \\
\text { Iranian industries, } \\
\text { Energy stream, } \\
\text { Assessment, } \\
\text { DEA, } \\
\text { EIA. }\end{array}$ & $\begin{array}{l}\text { that assigns Data Envelopment Analysis (DEA) to discover the performance of industrial } \\
\text { projects along with statistical tests. The objective of the current study prosecuted to discern } \\
\text { the cost/revenue analysis in statistical language. Therefore, the empirical equations and } \\
\text { SPSS Software of IBM } 20 \text { were employed in the analysis of financial reports. The findings } \\
\text { were succeeded to present linear relationships for the dependent and independent variables } \\
\text { and in full compliance with diagrams developed by SPSS software. The results of the DEA } \\
\text { model ended up with the emergence of an efficiency border for } 8 \text { industrial groups ( } 334 \\
\text { industries) around a range of } 0 \text { to } 0.4 \text { by scatter plot. There were no significant differences } \\
\text { between dependent and independent variables in different models assessed via T and F and } \\
\text { ANOVA tests. It can be concluded that the findings of the DEA model displayed by the } \\
\text { scatter plot are a benchmarking level for industrial projects once before complete } \\
\text { construction. }\end{array}$ \\
\hline
\end{tabular}

\section{INTRODUCTION}

The scope of statistical science is such that its key role in all sciences is clearly evident today. In this article, only a brief description of the employed parametric tests is mentioned. Parametric tests are used to compare data with normal distributions. These tests should not be used if the data do not follow the normal distribution. For example, the ANOVA statistical test is used to compare the mean of a quantitative variable with the normal distribution in more than two groups to check whether the mean of that variable is the same among the groups. The T-test is used to compare the values of a quantitative variable in more than two groups (which may be two independent groups or one group at two different times). By accessing small quantities of two types of independent and non-independent variables, various functions can be defined. Methods such as regression analysis and least squares can be used to determine the type of function obtained from the values. These methods are mostly used in the preparation and evaluation of analytical grading charts $[1,2]$. The dimension of a project depends on a variety of variables such as its capital, number of workers, production stream, and sales rates, etc. In the literature, the scale of small and medium-sized enterprises comprises up to 10,50 , and upper than 50 for micro, small and medium-sized industrial enterprises [3, 4].

Regardless of the dimension and scale of industrial projects all of them must go through the project identification steps in the EIA plan. The screening step of the EIA plan provides an inventory of availability in the initial assessment. Based on the initial assessment the framework of the project underpins financial and economic estimations, examining technologies and practices in the matrix of criteria and alternatives to select the best and optimized technology and moves to decision science theory. The public 
involvement in the project also configures the pollutants discovery and many other aspects of projects. The review of alternatives and criteria in reports of EIA is an indispensable step that determines assigning and recruiting relevant technologies in this regard. The expert ideas are taken into consideration in this step. After completing the review process and examining the alternatives, the decision comes into view with the reports of financial \& economic stability of the project. After this step project moves towards the implementation step and sustainability of the project is requested in the post-EIA plan [5-8].

DEA is a prominent efficiency assessment instrument that has widely employed in a variety of sciences these days. The configured DEA models comprised from CCR, BCC, IRS, DRS, GRS, AR (Assurance Region), NCN (Non-Controllable), NDSC (Non-Discretionary), BND (Bounded Variable), CAT (Categorical Variable), SYS (Different Systems), SBM-Oriented (Slacks-based Measure), SBM-NonOriented, Weighted SBM, Super-SBMOriented, Super-SBM-NonOriented, Super-Radial, Cost-GRS, New-Cost-GRS, Revenue-GRS, New-Revenue-GRS, Profit-GRS, New-Profit-GRS, Ratio (Revenue/Cost), Bilateral, Window, FDH, and Malmquist-Radial. The traditional DEA model was used in the performance analysis of 8 industrial groups of projects by the present study. The Friedman test is a statistical test in the pack of SPSS software and similar to the F test. It was applied as both ranking and weighing systems in Multi-Criteria Decision Making models in a situation of uncertainty $[9,10]$.

The objectives discussed by the current research encompass (1) developing a linear function based on recent costs of energy and revenue of products streams in the market of Tehran, Iran (2) conducting a regression analysis based on dependent (revenue) and independent (costs of energy stream) variables by SPSS software and empirical equations (3) investigating performance of industrial projects ( 8 groups of industrial projects individually) once before complete construction via DEA model displayed by scatter plot (4) introducing statistical tests to figure out significant differences between values and further analysis (any possible test). The novelty of the present research refers to the development of a linear function based on recent costs of energy and revenue of products streams (extracted from screening step of industrial projects in EIA plan) in the market of Tehran, Iran.

\section{LITERATURE REVIEW}

The financial efficiency of 85 Spanish insurance companies assessed by the DEA model and a linear regression plot depicted among the values obtained. Other statistical tests applied to further analyses of values. The variables employed in the DEA model encompassed 5 inputs and 1 output [11]. Shahroudi [12] developed a linear production function of $Y=2.44 \mathrm{~L} 0.081 \mathrm{~K} 0.97, \alpha+\beta \leq 1$; $\mathrm{Y}=2.374 \mathrm{~L} 0.656 \mathrm{~K} 0.974$ via SPSS analysis of kaab Douglas for Iranian small-scale industries. The SPSS and Minitab software's applied to assess data of forty-five enterprises in Iran. The findings resulted in underpinning a model along with weighing indices [13]. The effects of sustainability of new industries have investigated by Madhoushi and Nasiri [14] to figure out the significant relationship between circumstances in the expansion of industries via cox model and SPSS analysis. The weight restrictions of the DEA model in distribution networks have been taken into consideration regarding input, total cost, and various outputs. To analyze the results, the regression model applied to find the aggregation of data around the line [15]. The statistical tests of regression, correlation, etc. assigned to analyze data of financial, and social performances (13 groups of industries). The expert idea distinguished the values of weights of criteria. The significant differences among various alternatives determined [16]. The 51 Indian domestic banking industries have assessed to find the technical efficiency via both DEA and Tobit analysis during 2006-2007. It reported to average technical efficiency score of about 0.792. A scale efficiency deployed by significant differences caught up using SPSS software. The industries underwent ANOVA test, pair-wise comparison test, and stepwise regression by tabulated information [17]. The 29 datasets examined via conformal regression with uncertainty to guarantee predictions. Further analysis has done using boxplots, error bars, prediction error flow diagrams, etc. The prominent role of conformal regression proved in bioactivity prediction generation via confidence levels [18]. To evaluate the performance of Slovak enterprises in financial statement reports employed a prediction model along with multiple regression analysis from 2015 to 2016 . The results provided important points to recede the risk of bankruptcy in the assessed cases. A significant difference, correlation had obtained via t-test and Pearson correlation test and coefficients [19]. Both regression and Tobit analysis models have used to investigate obtained performance ranks via the DEA model for Indian airlines from 2005 to 2012. The links among drivers of technical, operational, and market performances had assessed and suggested to select the technical efficiency as the best evaluator of performance indicator [20]. Conventional and Islamic banking have taken into an investigation in terms of profitability, efficiency, and liquidity factors from 2013 to 2017. The statistical parameters of t-test, ratio analysis, and regression analysis requested to discover the differences between the two systems of banking [21]. The impact of green manufacturing scrutinized in the organizational performance in India. The performance estimated through the regression analysis with one dependent and 5 independent variables. It resulted in developing linear equations and relationships with maximum and minimum fitness levels of $50.4 \%$ to $77.9 \%$ for lines. The further analysis had done via correlation tests and sensitivity analysis. Finally, many models introduced for financial performance evaluation along with simulation models and validation of them [22]. A study evaluated the operating performance of 14 shipping industries based on financial indicators of assets, stockholder's equity (input variables) operating revenue, and net income (output variables) via the DEA-CCR model. Also, regression analysis assigned for the same purpose, and the findings of both models compared each other. The findings in ranking systems were different in models. Also, the application of regression analysis examined in a linear relationship versus the efficient borderline of the DEA model. The input and output variables were the vertical and horizontal axis of the diagram [23]. The Indian automotive industries examined for performance analysis via Tobin and financial statement analysis based on costs of production, net value-added, fixed capital, number of workers from 1980 to 2007. The statistical analysis tests configured by one dependent and 11 independent variables. The coefficient robust $\mathrm{z}$-value calculated for the independent variables. The negative and positive values of the coefficients tabulated by the way [24]. In the assessment of the performance of 25 Indian automobile companies applied data analysis mean, median, standard deviation as descriptive statistics $\&$ correlation, regression, ANOVA, the test of significance, and variety of other flow diagrams displayed in parallel with objectives followed with the present study from 2011 to 2015. A good statistical analysis conducted with valid results [25]. A dataset of 97 various kinds of Indian industries contains four groups considered to be assessed via statistical analysis such as t-test and mean difference, ANOVA test, etc. It resulted in identifying forty 
percent of globalized industries [26]. The regression analysis requested for existing variables of Iranian chemical industries registered on the Tehran stock exchange from 2005 to 2010. The relationship between variables and significant differences, $\mathrm{F}$ and $\mathrm{T}$ tests investigated. The linear relationships among variables of operating profit, net profit, and cash flows had proved. There were no significant differences between dependent and independent variables in different models assessed [27].

\section{METHODOLOGY}

The initial data of industrial projects were collected from incharge organizations of both Iranian industries and Iranian protection agency. The data were evaluated by the evaluator team in the screening step of the EIA plan. The screening step of industrial projects was provided the required information for the initial assessment. Then data were divided into two sections such as costs of energy and revenue of products. The below-mentioned tests were assigned to find the performance of industrial groups of projects according to Figure 1.

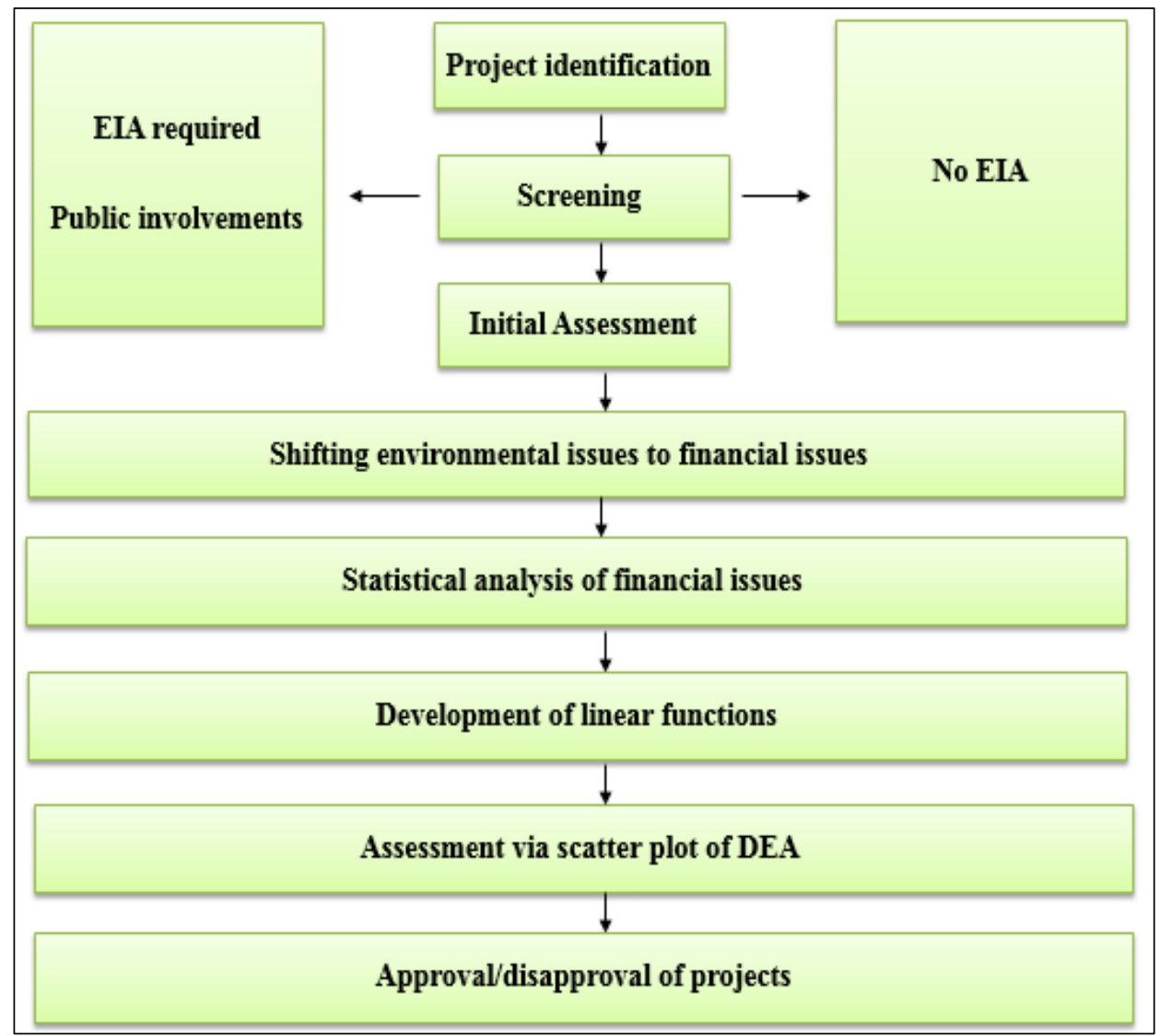

Figure 1. The evaluation steps of EIA and followed work for current research. Source: Author, (2021).

The costs of the energy stream encompassed the sum of outlays of water, power, fuel consumed, and salary of staff. The revenue of industries engulfs the income from selling industries products individually and annually in each group.

$$
\begin{gathered}
\mathrm{y}=a+b x \\
\mathrm{~b}=\sum(x \cdot y)-\sum x \cdot \frac{\sum y}{n} / \sum x^{2}-\frac{\left(\sum x\right)^{2}}{n} \\
\mathrm{a}=\overline{\mathrm{y}}-b x^{-} \\
\mathrm{r}=\sum\left(x-x^{-}\right)(y-\bar{y}) / \sqrt{ }\left(\sum\left(x-x^{-}\right)^{2} \cdot \sum(y-\bar{y})^{2}\right)
\end{gathered}
$$

For the regression equations, $\mathrm{n}$ is the number of observations, $x$ is the mean of all $x$-values, $y$ is the mean of all $y$ values, and $r$ is the coefficient of the correlation. With regard to this fact that the objective followed by the present research does not specifically include the performance analysis of industrial groups so the equations of the traditional DEA model united with the weighing system of the Friedman test were ignored to appear in the methodology section.

\section{RESULTS AND DISCUSSION}

\section{IV.1 IRANIAN INDUSTRIES}

By the present study, the Iranian industries comprised from 8 groups according to appendices such as Iranian Wood and Cellulose Industries (IWCI), Iranian Textile and Leather Industries (ITLI), Iranian Mining and Aggregate Industries (IMAI), Iranian Food Manufacturing and Processing Industries (IFMPI), Iranian Plastic Industries (IPI), Iranian Electronic Products Manufacturing Industries (IEPMI), Iranian Chemical Industries (ICI), and Iranian Household Appliance Industries (IHAI). The existing information the below, figures \& Table indicate the data of power, water, and fuel consumed and the number of employees as main industryspecific factors (energy stream) that estimated by the team of evaluators of Iranian organizations. The values have estimated for 8 industrial groups in the EIA plan initially. 
Hassanpour, ITEGAM-JETIA, Manaus, v.7, n.28, p. 4-15, Mar/Apr, 2021.

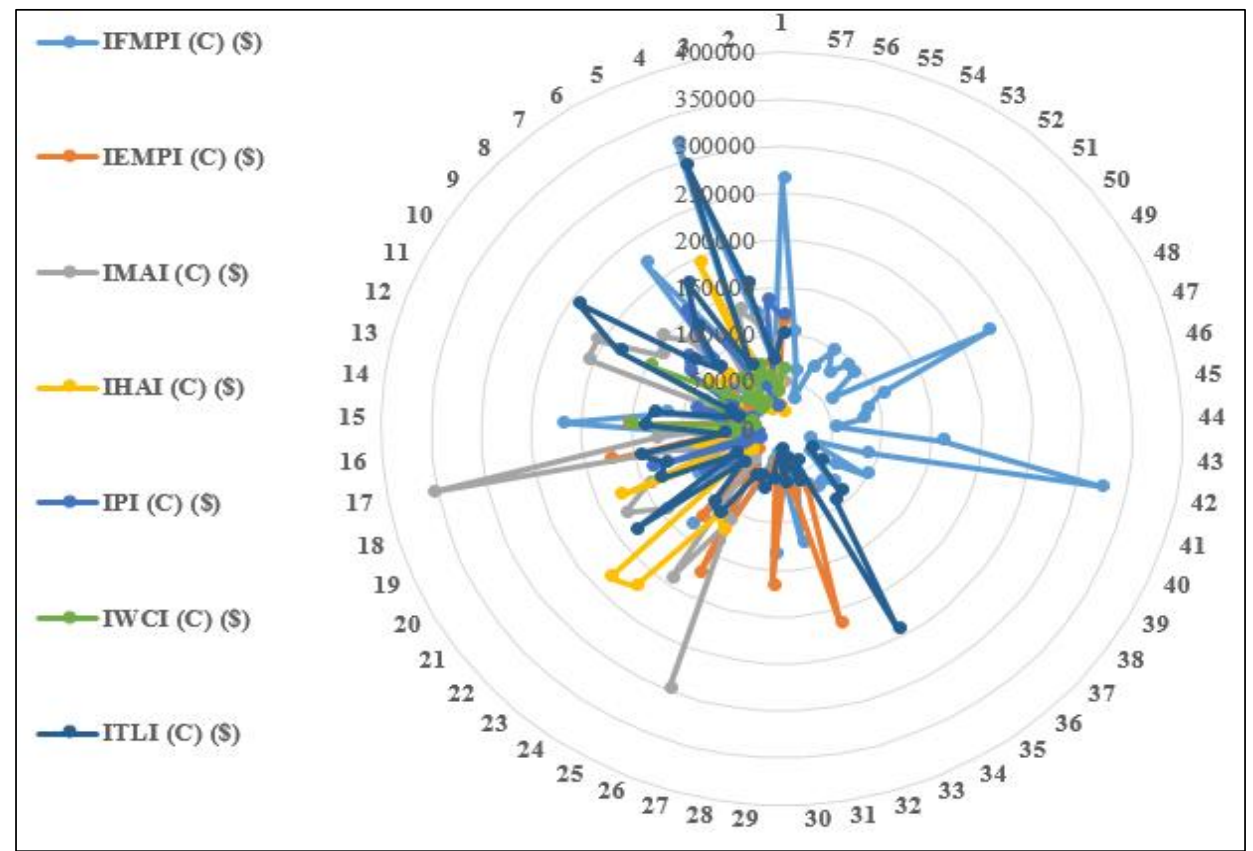

Figure 2: The costs (energy stream) of industrial groups.

Source: Author, (2021).

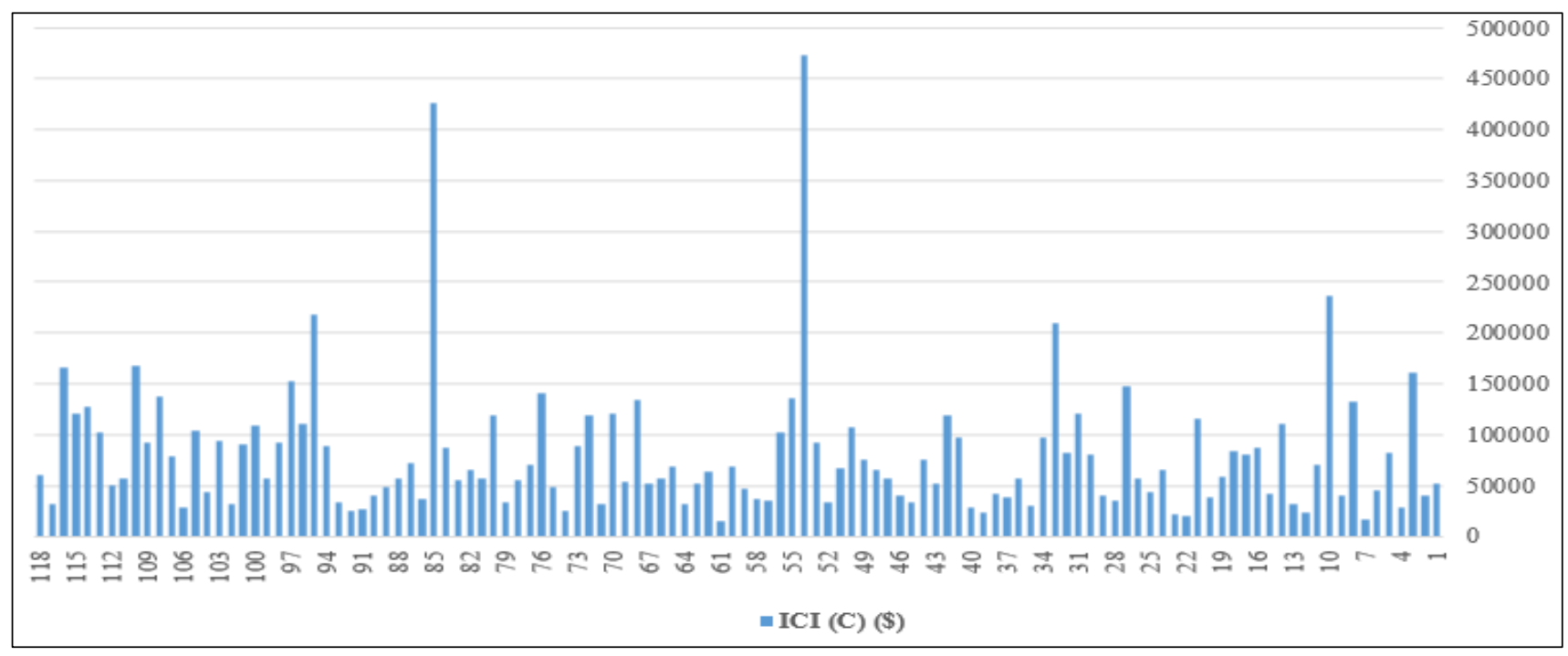

Figure 3: The costs (energy stream) of ICI.

Source: Author, (2021).

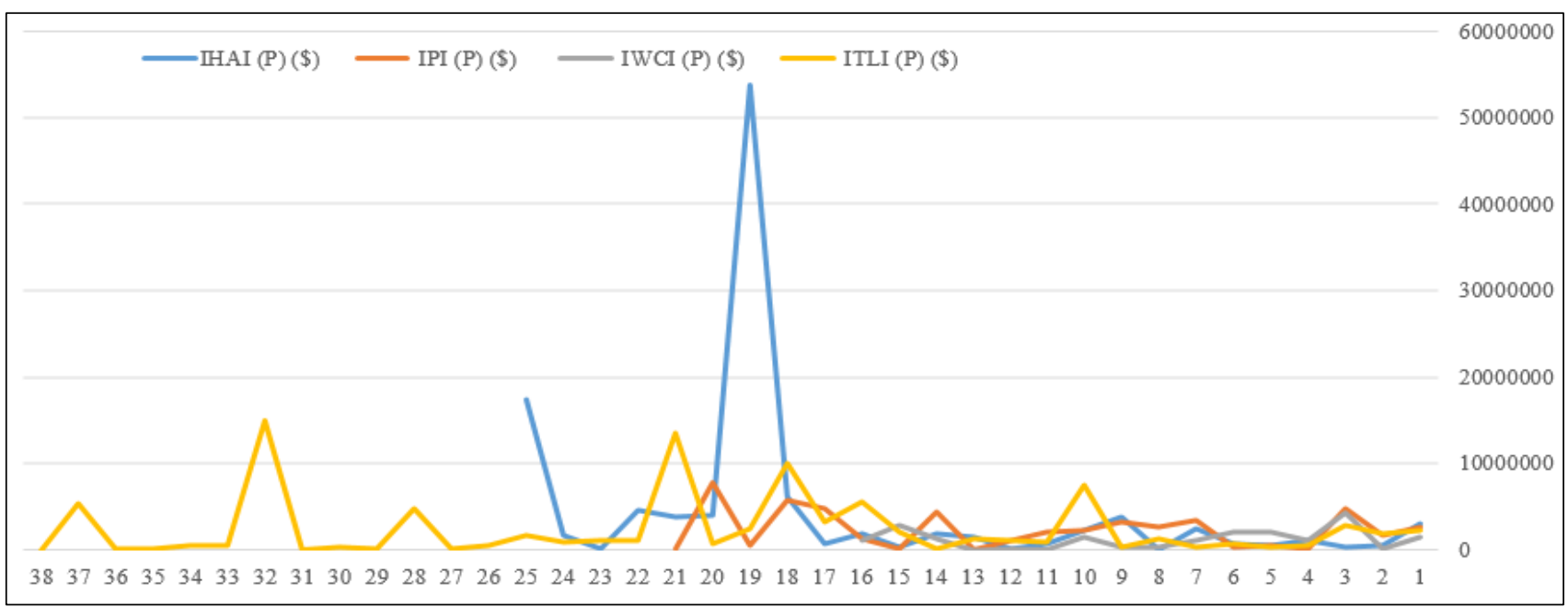

Figure 4: The revenue of industrial groups.

Source: Author, (2021). 
Table 1: The revenue of industrial groups.

\begin{tabular}{|c|c|c|c|c|}
\hline $\begin{array}{c}\text { IMAI (P) } \\
(\$)\end{array}$ & $\begin{array}{l}\text { IEMPI (P) } \\
(\$)\end{array}$ & $\begin{array}{l}\text { IFMPI (P) } \\
(\$)\end{array}$ & ICI (P) (\$) & \\
\hline 7269230770 & 4000000 & 8076923 & 1153846.154 & 50000 \\
\hline 1153846154 & 2000 & 1300000 & 1501000 & 81000 \\
\hline 500000 & 200000 & 1238076.92 & 6000000 & 5697992 \\
\hline 1200000 & 160000 & 536470 & 960000 & 33693600 \\
\hline 1200000 & 54000 & 3750000 & 1442308 & 1500000 \\
\hline 150000000 & 150000 & 1615384.6 & 250000 & 660000 \\
\hline 182692.3 & 300000 & 19384615.5 & 150000 & 1200000 \\
\hline 600000 & 250000 & 823384.61 & 2554070 & 2115384.62 \\
\hline 6923076.9 & 240000 & 2400000 & 520000 & 764307.7 \\
\hline 3070000 & 15000 & 380000000 & 110770 & 186300 \\
\hline 5769.23 & 1200000 & 57600 & 1350000 & 2884615.385 \\
\hline 5769230.77 & 400000 & 291600 & 58153.85 & 360000 \\
\hline 5192307.7 & 30000 & 1000000 & 173076.93 & 36000000 \\
\hline 557.5 & 3500000 & 7846153.85 & 38461153.85 & 200000 \\
\hline 390000 & 350000 & 7837500 & 100000 & 350000000 \\
\hline 3000000 & 1523076.9 & 2769230.77 & 130000 & 5400000 \\
\hline 4038461.5 & 1600 & 1600000 & 650000 & 5244000 \\
\hline 342000 & 200000 & 27594000 & 4320000 & 800000 \\
\hline 45000 & 310000 & 1923076.95 & 1090000 & 2769230.77 \\
\hline 356400 & 615384.61 & 3160000 & 585000 & 230000 \\
\hline 30000 & 3846153.84 & 3000000 & 240000 & 461538.5 \\
\hline 240000 & 630000 & 1609615.4 & 15120 & 1269230.8 \\
\hline 2000000 & 600000 & 5775000 & 100000 & 414000 \\
\hline 2300000 & 553846.16 & 1615384.6 & 2000000 & 42115385.6 \\
\hline 200000 & 2000000 & 6230769.24 & 200000 & 35000000 \\
\hline \multirow[t]{36}{*}{20000} & 1000000 & 5859230.77 & 153846.2 & 923077 \\
\hline & 307692.3 & 1121538.5 & 1700000 & 1000000 \\
\hline & 584615.4 & 1275000 & 942307.7 & 1000000 \\
\hline & 500000 & 7692307.7 & 2500000 & 5774859 \\
\hline & 900000000 & 3461538.4 & 1495384.5 & 2137500 \\
\hline & 540000 & 3346153.84 & 960000 & 19461538 \\
\hline & 8160000 & 1000000 & 634615.4 & 400000 \\
\hline & 207692.3 & 13148000 & 2307692.3 & 5400 \\
\hline & & 119000 & 74870.8 & 3240000 \\
\hline & & 3000000 & 24923076.9 & 3553846 \\
\hline & & 6000000 & 114400 & 1038461.5 \\
\hline & & 272750 & 1000000 & 2223076.9 \\
\hline & & 250000 & 50000 & 12500000 \\
\hline & & 243000 & 1442307.7 & 5384615.5 \\
\hline & & 16800 & 692307.7 & 38500000 \\
\hline & & 4147200 & 911538.5 & 22730770 \\
\hline & & 1400000 & 962350 & 15000 \\
\hline & & 18720000 & 2884615.4 & 4830572 \\
\hline & & 15000 & 1080000 & 240000 \\
\hline & & 750000 & 876923 & 125000 \\
\hline & & 12096 & 2700000 & 2307692.3 \\
\hline & & 990769.23 & 3600000 & 23100000 \\
\hline & & 2153846.15 & 4812692.3 & 1239300 \\
\hline & & 380134618 & 5184000 & 576923 \\
\hline & & 770000 & 10341000 & 3575000 \\
\hline & & 372000 & 17307.7 & 1538461.5 \\
\hline & & 16000000 & 2076923 & 1500000 \\
\hline & & 1900666 & 7427504.8 & 561538.5 \\
\hline & & 4000000 & 617616 & 2608695 \\
\hline & & 600000 & 18269.24 & 3370000 \\
\hline & & 3000000000 & 400000 & 11434615.4 \\
\hline & & 1920000 & 199038.5 & 2284615.4 \\
\hline & & & 50000 & 18000000 \\
\hline & & & 81000 & 12600000 \\
\hline & & & 5697992 & 500000 \\
\hline & & & & 3846153.9 \\
\hline
\end{tabular}

Source: Author, (2021).

In the figures and Table, the symbol of $\mathrm{P}$ and $\mathrm{C}$ means the revenue of products and costs of energy stream respectively. Tables 2 and 3 show the regression analysis of cost/revenue by SPSS software and empirical equations respectively. Figure 5 displays the linear regression diagrams of cost/revenue analysis of industrial groups.
Table 2: The regression analysis of cost/revenue.

\begin{tabular}{|c|c|c|c|c|c|}
\hline $\begin{array}{l}\text { Industries } \\
\text { /models }\end{array}$ & $\mathbf{R}$ & $\begin{array}{c}\mathbf{R} \\
\text { square }\end{array}$ & $\mathbf{F}$ & Sig. & $\begin{array}{c}\text { Standard } \\
\text { coefficient } \\
\text { beta }\end{array}$ \\
\hline \multirow{2}{*}{ ITLI } & \multirow{2}{*}{$0.132^{\mathrm{a}}$} & \multirow{2}{*}{0.017} & \multirow{2}{*}{0.638} & 0.430 & - \\
\hline & & & & $0.155 ; 0.430$ & 0.132 \\
\hline \multirow{2}{*}{ IHAI } & \multirow{2}{*}{$0.339^{\mathrm{a}}$} & \multirow{2}{*}{0.115} & \multirow{2}{*}{2.995} & 0.097 & - \\
\hline & & & & $0.097 ; 0.925$ & 0.339 \\
\hline \multirow{2}{*}{ ICI } & \multirow{2}{*}{$0.068^{\mathrm{a}}$} & \multirow{2}{*}{0.005} & \multirow{2}{*}{0.534} & 0.466 & - \\
\hline & & & & $0.320 ; 0.466$ & 0.068 \\
\hline \multirow{2}{*}{ IMAI } & \multirow{2}{*}{$0.208^{\mathrm{a}}$} & \multirow{2}{*}{0.043} & \multirow{2}{*}{1.085} & 0.308 & - \\
\hline & & & & $0.144 ; 0.308$ & -0.208 \\
\hline \multirow{2}{*}{ IWCI } & \multirow{2}{*}{$0.141^{\mathrm{a}}$} & \multirow{2}{*}{0.020} & \multirow{2}{*}{0.284} & 0.603 & - \\
\hline & & & & $0.603 ; 0.158$ & 0.141 \\
\hline \multirow{2}{*}{ IFMPI } & \multirow{2}{*}{$0.095^{\mathrm{a}}$} & \multirow{2}{*}{0.009} & \multirow{2}{*}{0.504} & 0.481 & - \\
\hline & & & & $0.481 ; 0.192$ & -0.095 \\
\hline \multirow{2}{*}{ IPI } & \multirow{2}{*}{$0.235^{\mathrm{a}}$} & \multirow{2}{*}{0.055} & \multirow{2}{*}{1.112} & 0.305 & - \\
\hline & & & & $0.305 ; 0.185$ & 0.235 \\
\hline \multirow{2}{*}{ IEMPI } & \multirow{2}{*}{$0.099^{\mathrm{a}}$} & \multirow{2}{*}{0.010} & \multirow{2}{*}{0.305} & 0.585 & - \\
\hline & & & & $0.585 ; 0.310$ & -0.099 \\
\hline \multicolumn{6}{|c|}{$\begin{array}{l}(\mathrm{P}=\text { revenue }) \text { dependent variable } \\
\text { a. predictor (constant). (ITLI }(\mathrm{C})) \\
\mathrm{R}=\text { Regression }\end{array}$} \\
\hline
\end{tabular}

\section{Source: Author, (2021).}

Table 3: The results of regression analysis.

\begin{tabular}{|c|c|c|c|c|}
\hline $\begin{array}{c}\text { Regression } \\
\text { /industrial } \\
\text { groups }\end{array}$ & $\mathbf{a}$ & b & Linear function (y) & $\mathbf{R}$ \\
\hline ITLI & 97923.10781 & 0.00236 & $\begin{array}{c}97923.10781+ \\
0.00236 \mathrm{X} \\
\end{array}$ & 0.132 \\
\hline IHAI & 73164.1681 & 0.001938 & $\begin{array}{c}73164.1681+ \\
0.001938 X \\
\end{array}$ & 0.339 \\
\hline ICI & 79844.96 & 0.000135 & $\begin{array}{c}79844.96+0.000135 \\
X \\
\end{array}$ & 0.068 \\
\hline IMAI & 129842.4025 & $-1.18 \mathrm{E}-05$ & $\begin{array}{c}129842.4025-1.18 \mathrm{E}- \\
05 \mathrm{X}\end{array}$ & -0.208 \\
\hline IWCI & 57845.1493 & 0.00438 & $\begin{array}{c}57845.1493+0.00438 \\
X \\
\end{array}$ & 0.14088 \\
\hline IFMPI & 98253.5 & $\begin{array}{c}-1.579 \mathrm{E}- \\
05\end{array}$ & $\begin{array}{c}98253.5-1.579 \mathrm{E}-05 \\
X \\
\end{array}$ & -0.095 \\
\hline IPI & 67680.8269 & 0.00454 & $\begin{array}{c}67680.8269+ \\
0.00454 X \\
\end{array}$ & 0.235 \\
\hline IEPMI & 73924.0551 & $-3.15 \mathrm{E}-05$ & $\begin{array}{c}\text { 73924.0551-3.15E- } \\
05 \text { X }\end{array}$ & -0.098 \\
\hline
\end{tabular}

Source: Author, (2021).

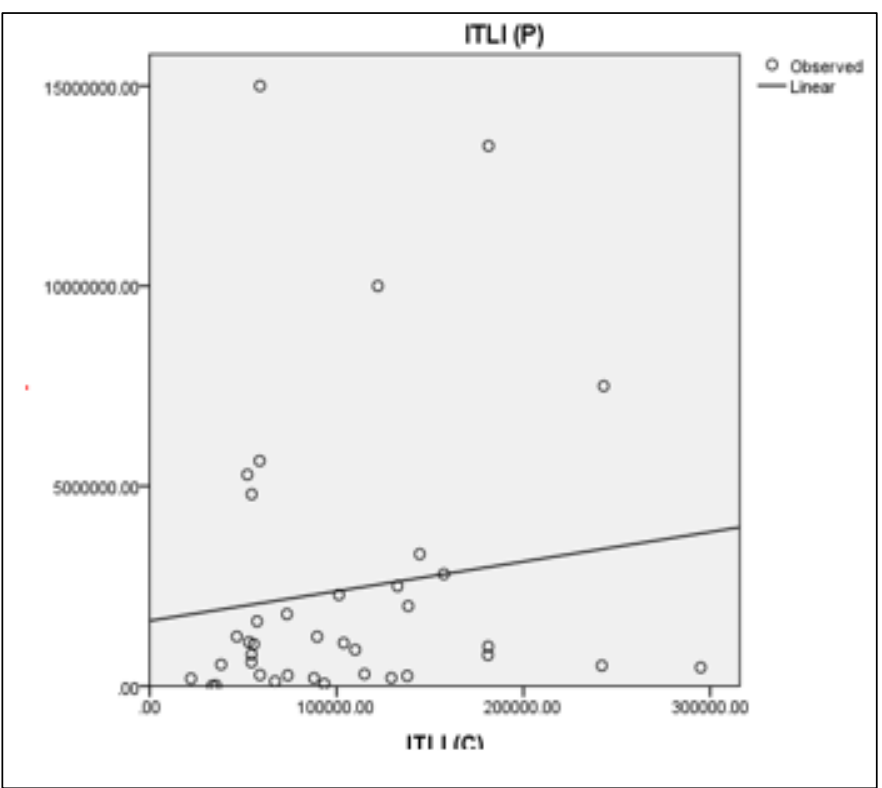

Figure 5a: The linear regression diagrams of cost/revenue analysis of industrial groups.

Source: Author, (2021). 
Hassanpour, ITEGAM-JETIA, Manaus, v.7, n.28, p. 4-15, Mar/Apr, 2021.

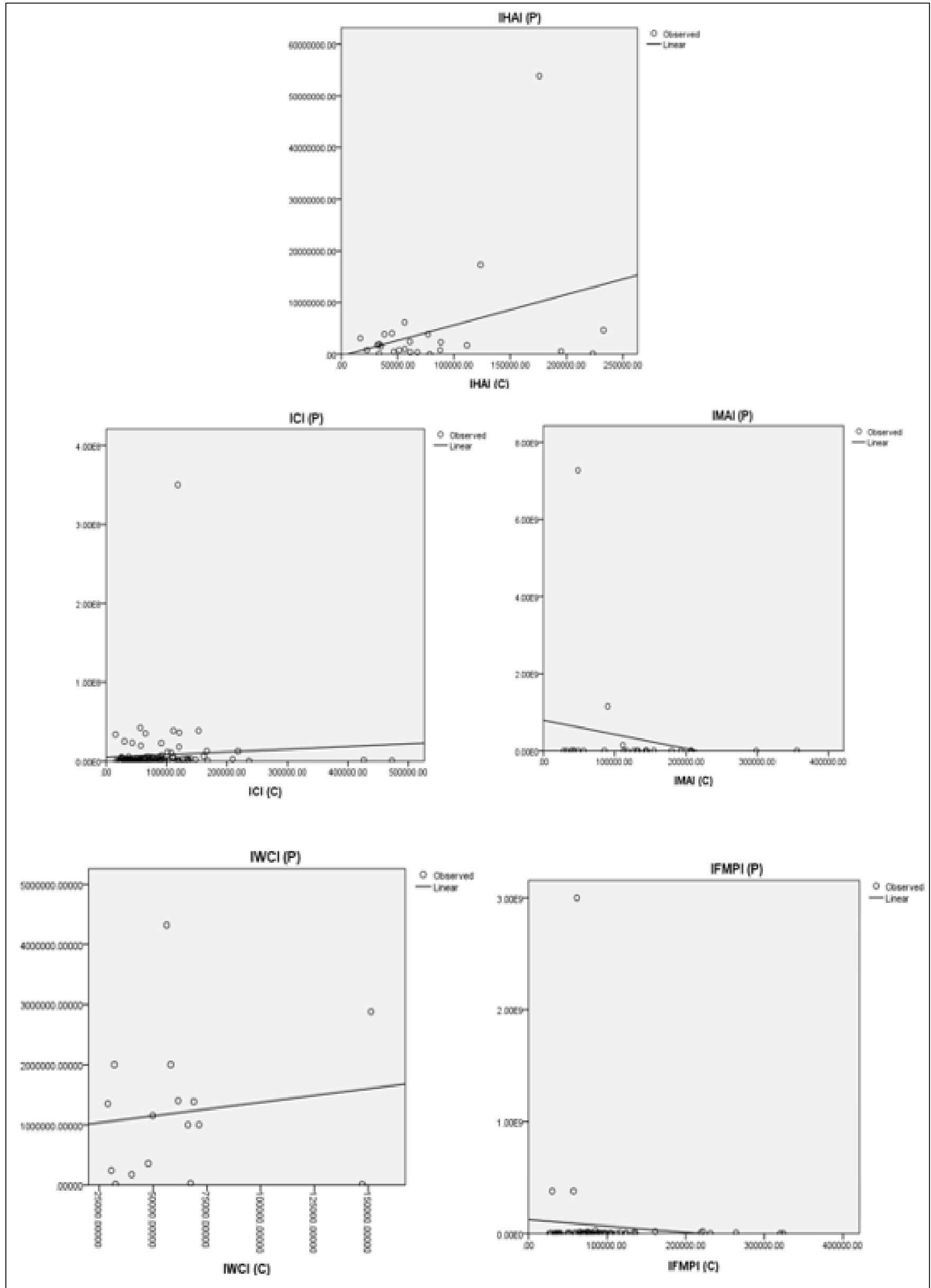

Figure 5b: The linear regression diagrams of cost/revenue analysis of industrial groups. Source: Author, (2021) 


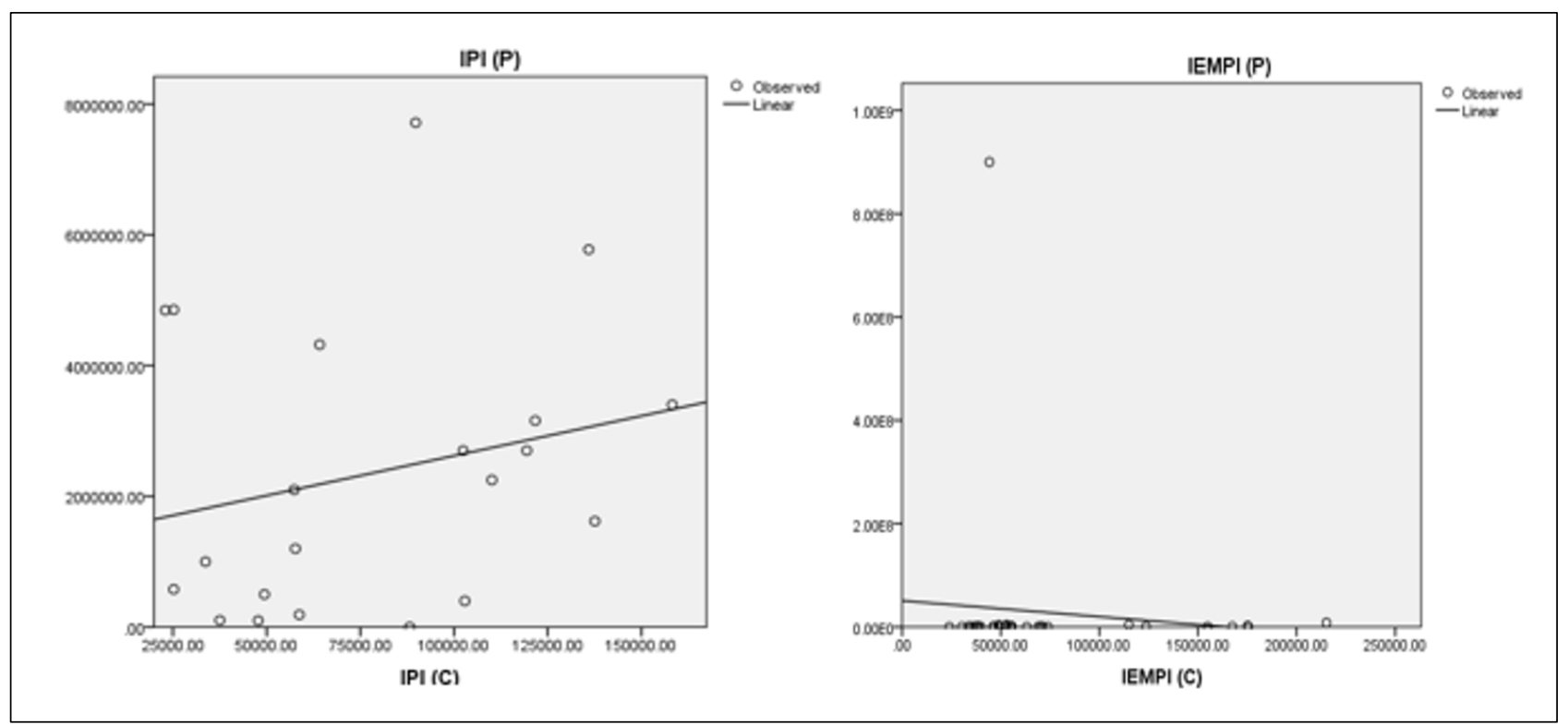

Figure 5c: The linear regression diagrams of cost/revenue analysis of industrial groups. Source: Author, (2021).

\section{IV.2 STATISTICAL ANALYSIS}

The null hypothesis test summary had shown that the distribution of all cost/revenue analysis in all industrial groups is normal via one-sample Kolmogorov Simonov test. So, it has resulted in the rejection of the null hypothesis in six analyses of industrial groups such as ITLI (P), IHAI (P), IMAI (P), IEMPI (P), IFMPI (P), and ICI (P). But keeping the same data in the null hypothesis test summary had proved the rejection of the null hypothesis in both analyses of cost/revenue (in all industrial groups) via related samples Friedman's two-way analysis of variance by ranks. By the way, the distribution of all industrial groups had appeared the same. The t-test analysis has manifested significant differences around ( $\mathrm{p}$-value $\leq 0.001,0.047,0.014$ ) in the analysis of cost/revenue for IWCI (P), IHAI (P), and ICI (P) among all industrial groups respectively. Using paired sample test analysis also presented the significant differences among IWCI (P, $\mathrm{C})$, IHAI $(\mathrm{P}, \mathrm{C})$, and ICI $(\mathrm{P}, \mathrm{C})$ around (p-value $\leq 0.001,0.050$, 0.016) respectively.

The mean ranks (weights) by Friedman test had released values of $12.81,10.34,11.75,11.78,12.56,8.88,13.50,11.25$, $7.25,4.25,5.31,4,6.69,4.19,6.69$, and 4.75 for ITLI (P), IWCI (P), IPI (P), IHAI (P), IMAI (P), IEMPI (P), IFMPI (P), ICI (P), ITLI (C), IWCI (C), IPI (C), IHAI (C), IMAI (C), IEMPI (C), IFMPI (C), ICI (C) respectively. So the highest and lowest ranks were devoted to IFMPI (P) and IHAI (C) respectively. The values of weights estimated by the Friedman test were used to find the efficiency ranks using the DEA model. Then the efficiency scores were displayed by scatter plot according to Figure 6 .

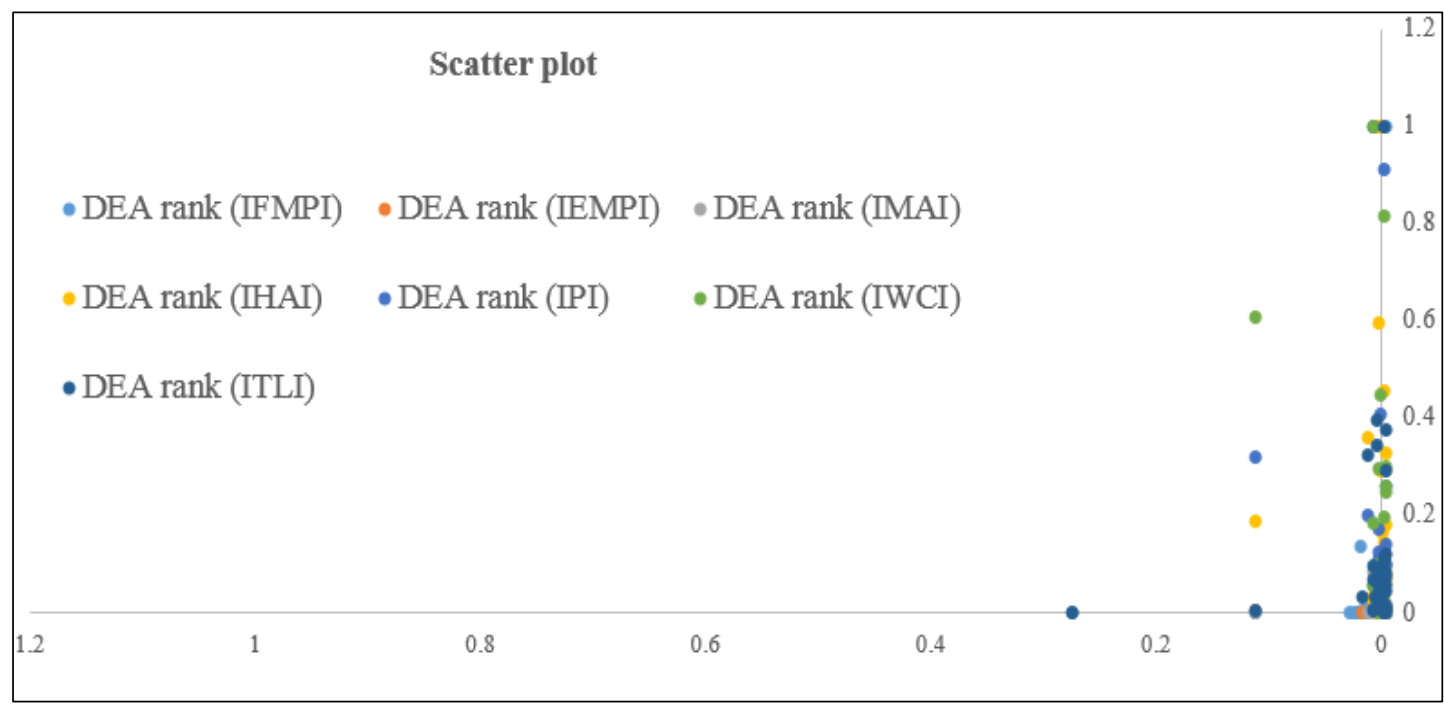

Figure 6: The scatter plot of DEA ranks of industrial groups.

Source: Author, (2021).

To calculate DEA has used the weights obtained from the Friedman test. The division of weighted output variable (products of industries in currency) to weighted input variable (cost of energy stream) was released the efficiency score according to scatter plot in Figure 6. Figure 6 proves that the most efficiency scores were scattered between a range of 0 to 0.4 . The values of DEA ranks for ICI did not appear in the plot due to negligible values in the industrial group. Figure 7 represents the sequence chart for values of ranks of industrial groups in the DEA model. 


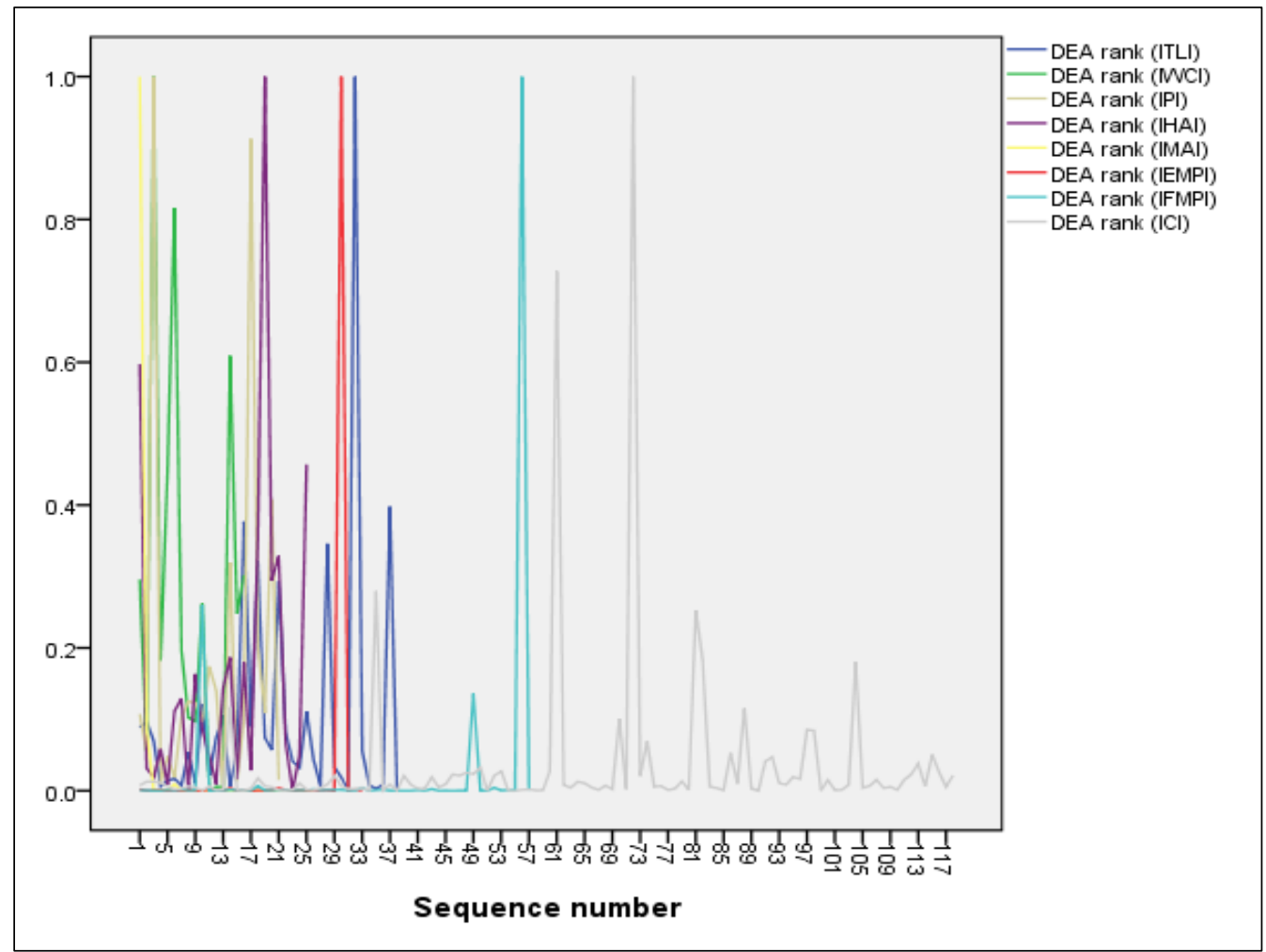

Figure 7: Sequence chart for values of ranks in DEA model.

Source: Author, (2021).

The application of sequence number refers to present interaction among various groups of alternatives in development stages when they are discussed in scenarios. The highest functionality emerges in linear expansion. The highest correlation came into view among values by both DEA rank values of IWCI and IPI with a quantity of around 0.632 . The paired samples test had shown a significant difference (p-values $\leq 0.014)$ among 8 industrial groups. The significance had appeared with ( $\mathrm{p}$-value $\leq$ $0.001,0.004)$ for industrial groups of ITLI, IWCI, IHAI, ICI, and IPI via t-test analysis respectively. Figure 8 portrays the scatter plot of cost versus revenue.

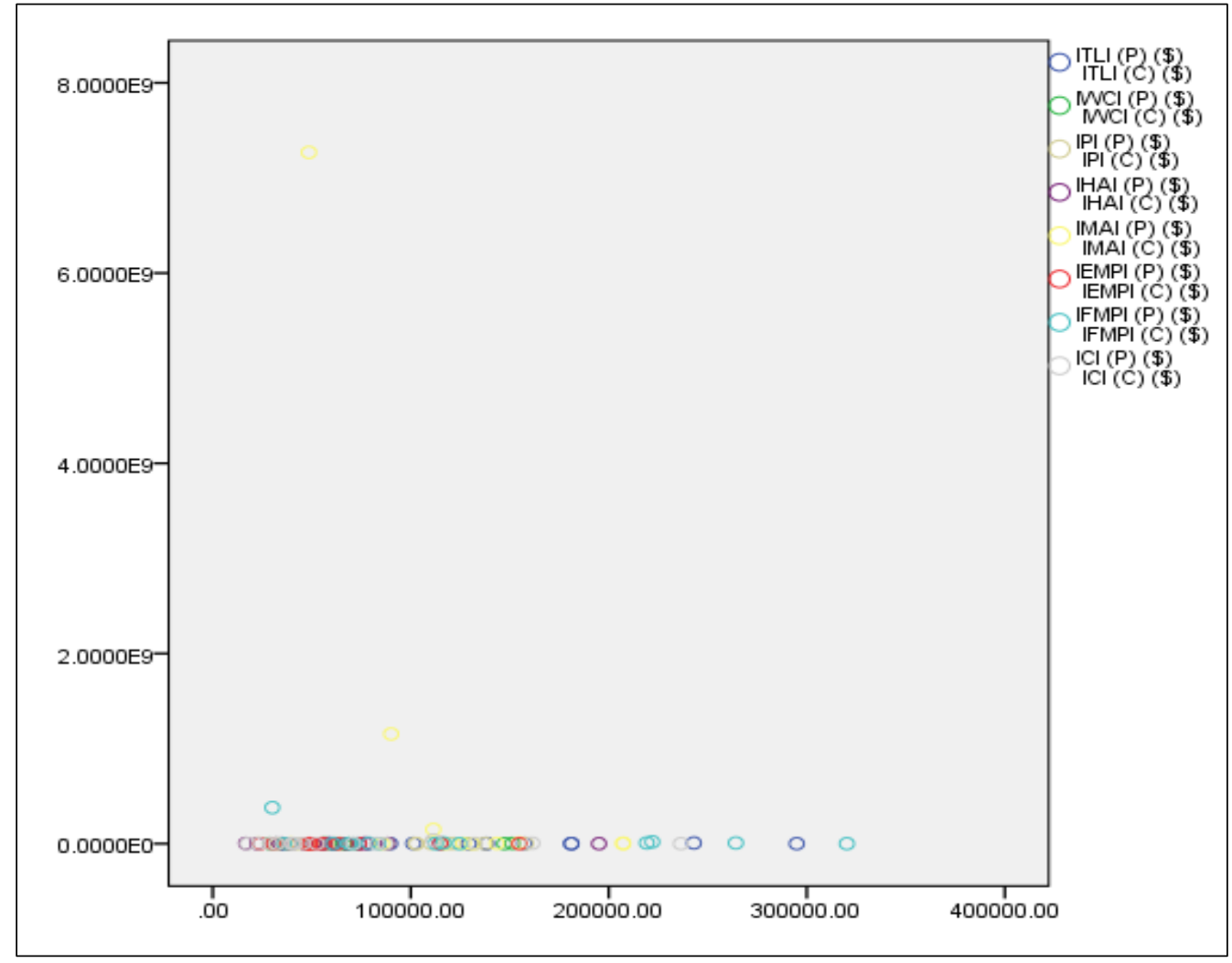

Figure 8: The scatter plot of cost versus revenue. Source: Author, (2021). 
According to Figure 8, the scatter plot drawn among data of cost/revenue analysis of all industrial groups is in a linear distribution. The findings prove the complete linear expansion and development of data in the scatter plot. Figure 9 presents the error bar plot of cost/revenue.

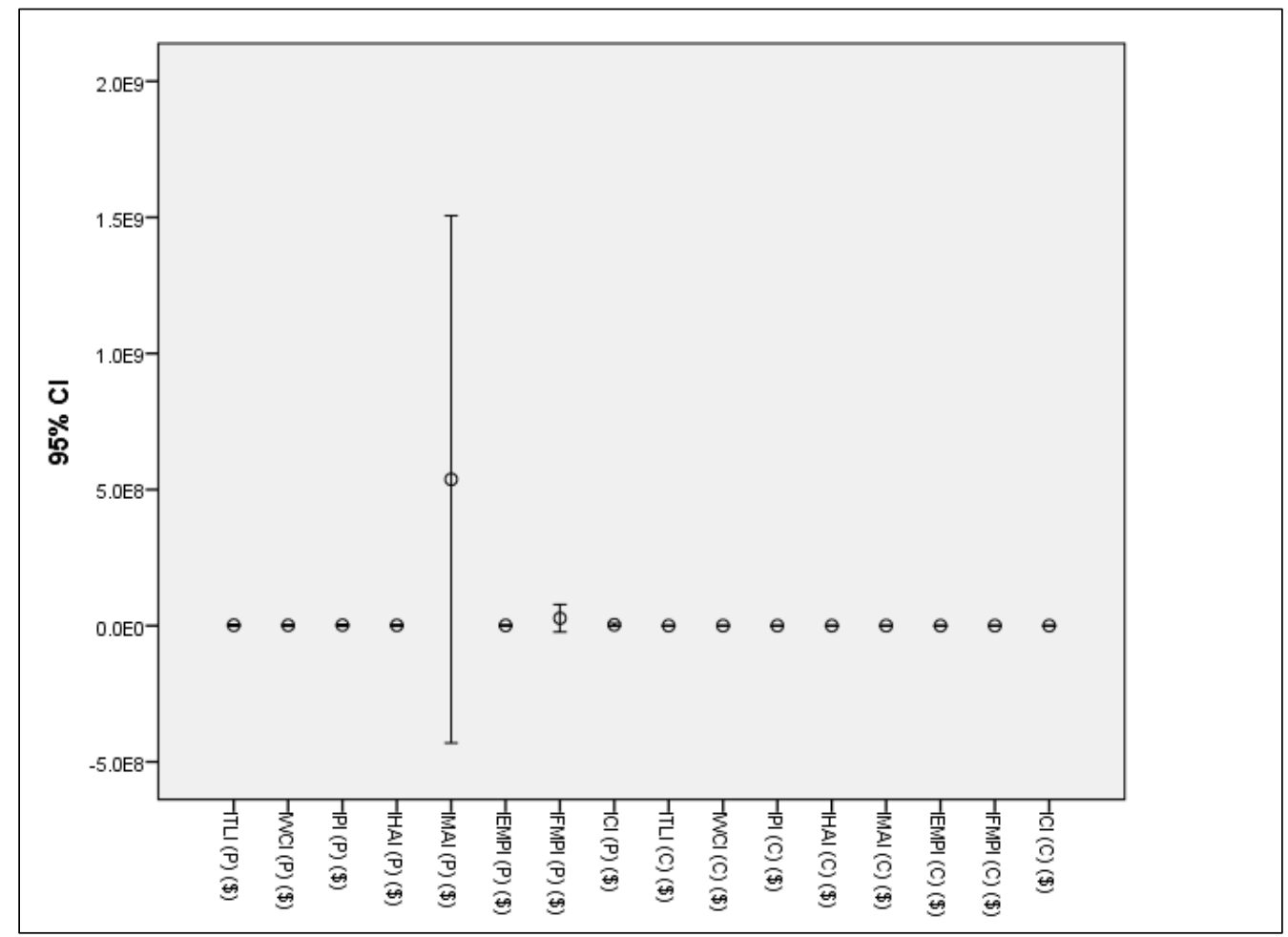

Figure 9: The error bar plot of costs/revenue for industrial groups. Source: Author, (2021).

The findings in figure 9 represent that there is no scatted data out of mean of data except in the data of IMAI (P) (\$). It means a wide distribution among data of IMAI (P) (\$) with low and high quantities scattered.

\section{CONCLUSION}

The present research introduced linear functions for each industrial group that can be expanded via Kaab Douglas modeling. The results of regression analysis via SPSS software occurred in full agreement and compliance with results obtained by empirical equations and linear flow diagrams deployed in the output of SPSS software. It was not observed significant differences among cost/revenue analysis of 8 groups of industrial projects. The good compliance of cost/revenue analysis came into view with linear progress in the scatter plot introduced. The expansion of the sequence number diagram followed a regular development in scenarios but not in a linear trend. The aggregation of DEA ranks of industrial groups had happened around a linear layout. The findings of the DEA model were displayed by scatter plot were a benchmarking level for this kind of assessment as it is for industrial projects once before complete construction. Future research orientation can be directed towards adding some new dependent and independent variables individually or mixed with financial ratio analysis to further processing the data. New types of DEA models united with the various weighing systems are another alternatives in further processing data.

\section{AUTHOR'S CONTRIBUTION}

Conceptualization: Malek Hassanpour. Methodology: Malek Hassanpour.
Investigation: Malek Hassanpour.

Discussion of results: Malek Hassanpour.

Writing - Original Draft: Malek Hassanpour.

Writing - Review and Editing: Malek Hassanpour.

Resources: Malek Hassanpour.

Supervision: Malek Hassanpour.

Approval of the final text: Malek Hassanpour.

\section{ACKNOWLEDGMENT}

This research was conducted as part of the corresponding author's Ph.D. research work (Entitled; Evaluation of 405 Iranian Industries). The tabulated data were picked up from the screening step of project identification in environmental impact assessment. The author thanked colleagues and evaluators of both the Iranian environment protection agency and Iranian industries organization for the data assessed.

\section{REFERENCES}

[1] Eisinga, R, Heskes, T., Pelzer, B., Grotenhuis, M. Exact p-values for pairwise comparison of Friedman rank sums, with application to comparing classifiers. BMC Bioinformatics. 2017, 18, 68, 2-18. DOI 10.1186/s12859-017-1486-2.

[2] Rezaee, M.J., and Ghanbarpour, T. Energy Resources Consumption Performance in Iranian Manufacturing Industries Using Cost/Revenue Efficiency Model, IJE Transactions C: Aspects, 2016, 29(9), 1282-1291. Doi: 10.5829/idosi.ije.2016.29.09c.14

[3] Al-Bdour JM. Jordan small and medium scale industries 2000-2010: periodical evaluation. European Scientific Journal. 2013, 9(7), 300-311.

[4] Kazan H, Ertok M, Ciftci C. Application of a Hybrid Method in the Financial Analysis of Firm Performance. Procedia - Social and Behavioral Sciences 195 (2015) 403 - 412. Doi: 10.1016/j.sbspro.2015.06.482. 
[5] Lohani BN, JW Evans, RR Everitt, H Ludwig, Richard AC, Shih-Liang TU. Environmental Impact Assessment for Developing Countries in Asia. Asian Development Bank. Volume 1 - Overview.1997; 1-356.

[6] Munn, RE, Environmental Impact Assessment, Principles and Procedures. Scope 5. John Wiley and Sons, New York. 1979.

[7] Barry S. EIA process strengthening - perspective and priorities. Pages 1-29 in Report of the EIA Process Strengthening Workshop, Canberra 4-7 April, 1995. Published by the Environmental Protection Agency, Canberra, Australia for the International Study of the Effectiveness of Environmental Assessment, 1997.

[8] Sonntag NC, Everitt RR, Rattie L, Colnett DL, Wolf CP, Truett J, Dorcey A, Holling CS. Cumulative Effects Assessment: A Context for Further Research and Development. Canadian Environmental Assessment Research Council (CEARC), Hull, QC. 99 pp. and appendices, 1986

[9] Cooper ww, Seiford LM, Tone K. Data Envelopment Analysis. Second edition. Springer Science-i-Business Media, LLC, 233 Spring Street, New York, NY 10013, USA. 2007, 1-512.

[10] Emrouznejad A, Podinovski V. Data Envelopment Analysis and Performance Management: Proceedings of the 4th International Conference on DEA, September 2004, Birmingham, UK, 417pp, ISBN: 090268373 X. 2004.

[11] Rodríguez-Pérez G, Slof J, Sola M, Torrent M, Vilardell I. Assessing the Impact of Fair-Value Accounting on Financial Statement Analysis: A Data Envelopment Analysis Approach. Abacus, 47, (1), 2011, 61-84. Doi: 10.1111/j.1467-6281.2011.00331.x.

[12] Shahroudi SM. Estimation of small-scale industries production functions. International Journal of Economics and Business Modeling. 2011; 2(2): 139-141.

[13] Hourali M, Fathian M, Montazeri A, et al. A Model for E-Readiness Assessment of Iranian Small and Medium Enterprises. Journal of Faculty of Engineering. 2008; 41(7): 969-985.

[14] Madhoushi M, Nasiri A. The Influence of Industry Characteristics on New Firms' Survival: Iranian Study. Australian Journal of Basic and Applied Sciences, 5(3): 653-661, 2011

[15] Bjorndal E, Bjorndal M, Camanho A. Weight Restrictions on Geography Variables in the DEA Benchmarking Model for Norwegian Electricity Distribution Companies. Thesis report. University of Porto, 2008. http://hdl.handle.net/11250/165047.

[16] Waddock SA, Graves SB. The corporate social performance- financial performance link. Strategic Management Journal, Vol. 18:4, 303-319 (1997).

[17] Kumar S, Gulati R. Technical efficiency and its determinants in the Indian domestic banking industry: an application of DEA and Tobit analysis. American J. Finance and Accounting. 2009, 1(3), 256-296.

[18] Svensson F, Aniceto N, Norinder U, Cortes-Ciriano I, Spjuth O, Carlsson L, Bender A. Conformal Regression for QSAR Modelling - Quantifying Prediction Uncertainty. J. Chem. Inf. Model. 2018, 58, 5, 1132-1140. https://doi.org/10.1021/acs.jcim.8b00054

[19] Valaskova K, Kliestik T, Svabova L, Adamko P. Financial Risk Measurement and Prediction Modelling for Sustainable Development of Business Entities Using Regression Analysis. Sustainability 2018, 10, 2144; doi: 10.3390/su10072144.

[20] Saranga H, Nagpal R. Drivers of operational efficiency and its impact on market performance in the Indian Airline industry. Journal of Air Transport $\begin{array}{llll}\text { Management } & 53 & \text { (2016) }\end{array}$ http://dx.doi.org/10.1016/j.jairtraman.2016.03.001.

[21] Salman A, Nawaz H. Islamic financial system and conventional banking: A comparison. Arab economic and business journal. 113 (2018) 155 - 167. http://dx.doi.org/10.1016/j.aebj.2018.09.003

[22] Rehman MA, Seth D, Shrivastava RL. Impact of green manufacturing practices on organizational performance in Indian context: An empirical study. Journal of $\begin{array}{lllll}\text { Cleaner } & \text { Production } & 137 & \text { (2016) }\end{array}$ http://dx.doi.org/10.1016/j.jclepro.2016.07.106.

[23] Lin WC, Liu CF, Chu CW. Performance efficiency evaluation of the Taiwan's shipping industry: an application of data envelopment analysis. Proceedings of the Eastern Asia Society for Transportation Studies. 5, 467 - 476, 2005.
[24] Pradhan JP, Singh N. Outward FDI and knowledge flows a study of the Indian automotive sector. ISID working paper 2008/10. Institute for Studies in Industrial Development 4, Institutional Area, Vasant Kunj, New Delhi - 110070

[25] Hiran S. Financial Performance Analysis of Indian Companies Belongs to Automobile Industry with Special Reference to Liquidity \& Leverage. International Journal of Multidisciplinary and Current Research. Int. J. of Multidisciplinary and Current research. 4, 2016, 39-51.

[26] Fetscherin M, Alon I, Jhonson JP. Export competitiveness patterns in Indian industries. International Business Journal. 22(3), 2012, 188-206. DO $10.1108 / 10595421211229637$

[27] Salehi M, Hematfar M. Comparing linear and non-linear relationships between accounting variables and dividend: Evidence of Iranian chemical industries. African Journal of Business Management. 2012, 6(6), 2143-2151. DOI: 10.5897/AJBM11.2484.

\section{APPENDIX}

\section{Section "IV.1 IRANIAN INDUSTRIES"}

\section{IV.1.1 Iranian Textile and Leather Industries (ITLI)}

ITLI comprised 38 various kinds of industries such as (1) Bag (NC=120000 No), (2) Carpet thread (NC=600t), (3) Cotton spinning ( $\mathrm{NC}=1400 \mathrm{t})$, (4) Jeans ( $\mathrm{NC}=81000 \mathrm{No})$, (5) Leather artifacts ( $\mathrm{NC}=90000 \mathrm{No}$ ), (6) Leather shoes ( $\mathrm{NC}=135000$ pairs), (7) Quilts, mattresses and pillows ( $\mathrm{NC}=85000 \mathrm{No})$, (8) Raw leather ( $\left.\mathrm{NC}=618300 \mathrm{Ft}^{2}\right)$, (9) Sewing and embroidery thread $(\mathrm{NC}=150 \mathrm{t})$, (10) Spinning (NC=2500t), (11) Tannery $(\mathrm{NC}=45500$ skin covers+214.988t), (12) Underwear (embroidered series) (NC=350000 No), (13) Wicker oil burner ( $\mathrm{NC}=620000 \mathrm{No}),(14)$ Spinning the woolen yarn $(\mathrm{NC}=306 \mathrm{t}),(15)$ Knitting cotton, synthetic fibers $\left(\mathrm{NC}=1000000 \mathrm{~m}^{2}\right),(16)$ Band and medical wound texture gas $(\mathrm{NC}=1407659$ No), (17) Rachel Curtain Fabrics $(\mathrm{NC}=330000 \mathrm{~m}),(18)$ Mink blankets $\left(\mathrm{NC}=500000 \mathrm{~m}^{2}\right),(19)$ Woolen blanket (NC=131500 No), (20) Spinning wool $(\mathrm{NC}=263.5 \mathrm{t})$, (21) Palash and blanket $\left(\mathrm{NC}=2250000 \mathrm{~m}^{2}\right),(22)$ Winter clothing $(\mathrm{NC}=137500$ No), (23) Clothing (shirt) ( $\mathrm{NC}=135000 \mathrm{No}$ ), (24) Knitted Tricot (NC=130t), (25) Fishing net $(\mathrm{NC}=270 \mathrm{t})$, (26) Stinger mosquito net $\left(\mathrm{NC}=300000 \mathrm{~m}^{2}\right),(27)$ Socks (NC=243000 jeans), (28) Crust leather $\left(\mathrm{NC}=2398000 \mathrm{Ft}^{2}\right)$, (29) Cotton gloves $(\mathrm{NC}=62400$ pair), (30) Leather gloves (NC=70000 pair), (31) Wipes (Cleansing) ( $\mathrm{NC}=4000$ yard), (32) Ribbon Weaving ( $\mathrm{NC}=3000000 \mathrm{~m})$, (33) Carpet coverage ( $\mathrm{NC}=54000 \mathrm{No}$ ), (34) Spinning silk (NC=102.8t), (35) Zipper $(\mathrm{NC}=3000000 \mathrm{~m}),(36)$ Animal skin pickle $(\mathrm{NC}=200000 \mathrm{No}),(37)$ Raw silk fabrics $(\mathrm{NC}=330000 \mathrm{~m})$, (38) Layer on diapers and sanitary pads $\left(\mathrm{NC}=8750 \mathrm{~m}^{2}\right)$.

\section{IV.1.2 Iranian Household Appliance Industries (IHAI)}

Types of IHAI based on NC comprised 25 industries such as Earphone (20000 No) (1), Hairdryer Handheld (100000 No) (2), Household ventilator (100000 No) (3), Household crystal containers (500t) (4), Pyrex glass containers (100000 No) (5), Semi-Automatic Washing Machine (10000 No) (6), Tea flask (100000 No) (7), Teflon containers (211t) (8), Water Cooler (20000 No) (9), Gas oven (12000 No) (10), Steam iron (20000 No) (11), Juicer (48000 No) (12), Electrical miller and mixer (20000 No) (13), Steam cooked double glazed steel (50000 No) (14), Electrical stove (30000 No) (15), Gas stove (20000 No) (16), Semiautomatic electric cooker (20000 No) (17), Ceiling fan (assembly) (50000 No) (18), Desktop fan (100000 No) (19), Household vacuum cleaner (assembly) (30000 No) (20), Meat grinders (assembled) (40000 No) (21), Chinese dishes (800t) (22), Chinese decorative dishes (500t) (23), Samovar (electric and oil) (82500 No) (24), Household refrigerator (15000 No) (25). 


\section{IV.1.3 Iranian Chemical Industries (ICI)}

Types of ICI based on NC comprised 118 industries such as Animal Feed from Agricultural Waste $(\mathrm{NC}=10000 \mathrm{t})(1)$, Animal drugs $(\mathrm{NC}=500 \mathrm{t}+50000$ No) (2), Ammonium Chloride $\left(\mathrm{NC}=1500 \mathrm{t}+2000 \mathrm{t} \mathrm{NaSO}\right.$ ) (3), Antifreeze $\left(\mathrm{NC}=960 \mathrm{~m}^{3}\right)$ (4), Baby carriage $(\mathrm{NC}=25000 \mathrm{No})(5)$, Blood Powder $(\mathrm{NC}=500 \mathrm{t})$ (6), Buds of different seeds $(\mathrm{NC}=150 \mathrm{t}) \quad(7)$, Barium carbonate $(\mathrm{NC}=3000 \mathrm{t}+1187 \mathrm{t}$ solfide sodium) $(8)$, Braided wax plates $(\mathrm{NC}=$ 130t) (9), Calcium carbonate (light and active) $(\mathrm{NC}=19200 \mathrm{t})(10)$, Calcium carbide $(\mathrm{NC}=1350 \mathrm{t})(11)$, Clothes hanger and pin (NC=504000 No) (12), Disinfectants ( $\mathrm{NC}=900000$ L) (13), Fiberglass boat $(\mathrm{NC}=5000 \mathrm{No})(14)$, Fiberglass pieces $(\mathrm{NC}=100 \mathrm{t})$ (15), Fragrant aromas $(\mathrm{NC}=130 \mathrm{t}) \quad(16)$, Glass- strip away $(\mathrm{NC}=650 \mathrm{t})(17)$, Glucose from starch $(\mathrm{NC}=2160 \mathrm{t})$ (18), Healthy Soap ( $\mathrm{NC}=1090 \mathrm{t})$ (19), Helmet ( $\mathrm{NC}=65000$ No) (20), High pressure hoses $(\mathrm{NC}=240 \mathrm{t})(21)$, Household Lighting Candles $(\mathrm{NC}=7560 \mathrm{No}$ ) (22), Insecticide coil ( $\mathrm{NC}=50000 \mathrm{No}$ ) (23), Isolator $\left(\mathrm{NC}=2000000 \mathrm{~m}^{2}\right)(24)$, Kitchen lighter $(\mathrm{NC}=100000 \mathrm{No})(25)$, Knife with injectable handle ( $\mathrm{NC}=800000 \mathrm{No})(26)$, Adhesive plaster $(\mathrm{NC}=1700 \mathrm{t})(27)$, Lining materials and insulating gas pipes $(\mathrm{NC}=3500 \mathrm{t})$ (28), Liquid fertilizer $(\mathrm{NC}=1250 \mathrm{t})$ (29), Matches $(\mathrm{NC}=7776000 \mathrm{No})$ (30), Mechanical disposable lighters (5000000 No) (31), Medicinal glycerin $(\mathrm{NC}=1500 \mathrm{t})$ (32), Melamine dishes $(\mathrm{NC}=1000 \mathrm{t})$ (33), Metal flexible hose pipes $(\mathrm{NC}=309 \mathrm{t})(34)$, Nitrobenzene $(\mathrm{NC}=1620 \mathrm{t})(35)$, Potassium chloride $(\mathrm{NC}=400 \mathrm{t})$ (36), Printing ink (NC=500t) (37), Rubber parts $(\mathrm{NC}=25 \mathrm{t})(38)$, Shoe wax $(\mathrm{NC}=3750000 \mathrm{No})$ (39), Soft polyurethane foam $(\mathrm{NC}=6000 \mathrm{t})(40)$, Starch from wheat $(\mathrm{NC}=1580 \mathrm{t})(41)$, Throwaway crockery $(\mathrm{NC}=962.35 \mathrm{t})(42)$, Tooth brush $(\mathrm{NC}=5000000 \mathrm{No})$ (43), Detergents (Shampoo, etc) $(\mathrm{NC}=1080 \mathrm{t})(44)$, Welding glasses ( $\mathrm{NC}=50000 \mathrm{No})$ (45), Insecticide spray containing flavoring materials $(\mathrm{NC}=2700000 \mathrm{No})(46)$, Acetic acid ester $(\mathrm{NC}=1200 \mathrm{t})$ (47), Phthalic anodic esters ( $\mathrm{NC}=970 \mathrm{t})(48)$, Calcium stearates $(\mathrm{NC}=2592 \mathrm{t})$ (49), Boric acid $\left(2700 \mathrm{t}+3600 \mathrm{t} \mathrm{NaSO}_{4}\right)(50)$, Hydrochloric acid (NC=3000t) (51), Chromic acid (270t) (52), Zinc oxide $\left(500 t+887.5 \mathrm{t} \quad \mathrm{NaSO}_{4}\right)(53)$, Oxygen; $\mathrm{Ar}$ and $\mathrm{N}_{2}$ $\left(\mathrm{NC}=3643200 \mathrm{~m}^{3}\right)$ (54), Alcohol from beet molasses $(\mathrm{NC}=5000$ No) (55), Types of gaskets (200t) (56), Acid and distilled water $\left(\mathrm{NC}=1725 \mathrm{~m}^{3}\right)$ (57), Rubber plugs $(\mathrm{NC}=25 \mathrm{t})$ (58), Sprinkler $(\mathrm{NC}=81000 \mathrm{No})(59)$, Sodium hypochlorite $(\mathrm{NC}=837900$ gallon) (60), Recycling silver from film and its solution $(\mathrm{NC}=40.40 \mathrm{t})(61)$, Industrial Paraffin ( $\mathrm{NC}=3000 \mathrm{t})$ (62), Raw silk fabrics $(\mathrm{NC}=330000$ m) (63), Pacifier ( $\mathrm{NC}=300000 \mathrm{No}$ ) (64), Unsaturated polyester $(\mathrm{NC}=1000 \mathrm{t})(65)$, Bleach powder $(\mathrm{NC}=2700 \mathrm{t})(66)$, Electrostatic coating $\left(\mathrm{NC}=81000 \mathrm{~m}^{2}\right)(67)$, Tri-calcium phosphate $(\mathrm{NC}=15000 \mathrm{t})$ (68), Hub and rubber ball (NC=360000 No) (69), Synthetic leather of polyurethane $\left(\mathrm{NC}=12000000 \mathrm{~m}^{2}\right)(70)$, Gum stick $(\mathrm{NC}=200000$ No) (71), Wood gum (polyvinyl acetate) $(\mathrm{NC}=7000 \mathrm{t})(72)$, Shoe adhesive $(\mathrm{NC}=1800 \mathrm{t})(73)$, Medical and sanitary adhesives ( $\mathrm{NC}=45600000 \mathrm{No}$ ) (74), Toothpastes and health cosmetics (NC=800t) (75), Hexagon pen ( $\mathrm{NC}=24000000 \mathrm{NO})$ (76), Pen $(\mathrm{NC}=2000000 \mathrm{No})(77)$, Plugs and screws head $(\mathrm{NC}=800000 \mathrm{No})$ (78), Diethyl ether ( $\mathrm{NC}=100 \mathrm{t})(79), \mathrm{CO}_{2}(\mathrm{NC}=1800 \mathrm{t})(80)$, Epoxy resin $(\mathrm{NC}=5475 \mathrm{t})(81)$, Alkyd resin $(\mathrm{NC}=17500 \mathrm{t})(82)$, Bakelite resin $(\mathrm{NC}=2000 \mathrm{t})(83)$, Resin; urea formaldehyde gum $(\mathrm{NC}=1000 \mathrm{t})$ (84), Dyeing and printing of fabrics $\left(\mathrm{NC}=2000000 \mathrm{~m}^{2}\right)(85)$, Transformer Oil $\left(\mathrm{NC}=8100 \mathrm{~m}^{3}\right)(86)$, Used motor oil and grease recycling $\left(\mathrm{NC}=3000 \mathrm{~m}^{3}+750 \mathrm{t}\right.$, grease) (87), Drying oils (500t+1000t wastes) (88), Rubber profiles (200t) (89), Insecticide spray ( $\mathrm{NC}=2700 \mathrm{No}$ ) (90), Rubber glass head ( $\mathrm{NC}=3240000 \mathrm{No}$ ) (91), Canopy ( $\mathrm{NC}=1540 \mathrm{t})$ (92), Agricultural liquid pesticides, Butachlor $(\mathrm{NC}=750 \mathrm{t})(93)$, Zinc sulfate $(\mathrm{NC}=3400 \mathrm{t})(94)$, Sodium sulfate $\quad(\mathrm{NC}=25000 \mathrm{t}) \quad(95)$, Alkyl benzene sulphonation
( $\mathrm{NC}=5000 \mathrm{t})$ (96), Sodium sulfite $(\mathrm{NC}=5000 \mathrm{t})(97)$, Sodium sulfide $(\mathrm{NC}=3000 \mathrm{t})(98)$, Sodium silicate $(\mathrm{NC}=3000 \mathrm{t})(99)$, Drip irrigation system $(\mathrm{NC}=1000 \mathrm{No}+383.9 \mathrm{t})(100)$, Glasses frames $(\mathrm{NC}=80000$ No) (101), Oil filter recycling $(\mathrm{NC}=2000 \mathrm{t})(102)$, Thermos and ice box $(\mathrm{NC}=150000 \mathrm{No})(103)$, Industrial and consumable taps ( $\mathrm{NC}=3000000 \mathrm{No}$ ) (104), Teflon strips ( $\mathrm{NC}=12393000 \mathrm{No})$ (105), Hair comb ( $\mathrm{NC}=1000000 \mathrm{No})(106)$, Glass artifacts $(\mathrm{NC}=1787.5 \mathrm{t})$ (107), Industrial crystals $(\mathrm{NC}=1000 \mathrm{t}) \quad(108)$, Spectacle glass (NC=500000 pairs) (109), Chinese insulator $(\mathrm{NC}=730 \mathrm{t})(110)$, Ceramic magnet $(\mathrm{NC}=869565 \mathrm{~m})$ (111), Tape (for electronic equipment) ( $\mathrm{NC}=3370000 \mathrm{No}$ ) (112), Fruit concentrate (NC= 19820t) (113), Shuttered windows ( $\mathrm{NC}=330000 \mathrm{No})$ (114), Hygiene products made of artificial stone $(\mathrm{NC}=4500 \mathrm{t})(115)$, Household, industrial and medical gloves $(\mathrm{NC}=12600000$ pair $)$ (116), Metal octet of $\mathrm{Ca}, \mathrm{Zn}, \mathrm{Mn}$, Co $(\mathrm{NC}=1000 \mathrm{t})$ (117), Refrigerator above zero for crops $(\mathrm{NC}=5000 \mathrm{t})(118)$.

\section{IV.1.4 Iranian Mining and Aggregate Industries (IMAI)}

IMAI encompassed 26 various types of industries as (1) Bitumen blown 90/15 (NC= 27000t), (2) Building plaster ( $\mathrm{NC}=150000 \mathrm{t})$, (3) Ceramic dishes $(\mathrm{NC}=250 \mathrm{t})$, (4) Ceramic tiles $\left(\mathrm{NC}=600000 \mathrm{~m}^{2}\right),(5)$ Floor Tiles $\left(\mathrm{NC}=600000 \mathrm{~m}^{2}\right),(6)$ Glazed tile and ceramic $(\mathrm{NC}=150000 \mathrm{t}),(7)$ Gypsum $(\mathrm{NC}=500$ packages $),(8)$ Industrial ceramic parts $(\mathrm{NC}=300 \mathrm{t}), \quad$ (9) Ceramic brick (NC=30000000 moulds), (10) Firebrick (NC=10000t), (11) Façade brick (NC=30000 pieces), (12) Semi-automatic brick (NC=30000000 moulds), (13) Hot asphalt (NC=135000t), (14) Building lime (NC=75000t), (15) Orthopedic bandage ( $\mathrm{NC}=1300000$ rolls), (16) Rock wool ( $\mathrm{NC}=1500 \mathrm{t}),(17)$ Glass wool $(\mathrm{NC}=7000 \mathrm{t}),(18)$ Stone powder and mosaic $(\mathrm{NC}=18000 \mathrm{t}),(19)$ Precast pressed beam and concrete pile ( $\mathrm{NC}=15000$ pieces), $(20)$ Gypsum prefabricated walls $\left(\mathrm{NC}=356400 \mathrm{~m}^{2}\right)$, (21) Prefabricated wooden wall by wood powder $\left(\mathrm{NC}=15000 \mathrm{~m}^{3}\right)$, (22) Cutting granite stone $\left(\mathrm{NC}=30000 \mathrm{~m}^{2}\right),(23)$ Grindstone $(\mathrm{NC}=500 \mathrm{t}),(24)$ Broken stone and debris washed $(\mathrm{NC}=200000 \mathrm{t})(25)$ Mineral powders $(\mathrm{NC}=200000 \mathrm{t}),(26)$ Cement asbestos tube $(\mathrm{NC}=500 \mathrm{t})$.

\section{IV.1.5 Iranian Wood and Cellulose Industries (IWCI)}

IWCI included 16 types of industries based on confirmation information in IIO such as (1) Cooler bangs $(\mathrm{NC}=1400 \mathrm{t})$, (2) Carton $(\mathrm{NC}=1500 \mathrm{t})$, (3) Industrial drying wood $(\mathrm{NC}=7500 \mathrm{t})$, (4) Hydrophilic cotton $(\mathrm{NC}=400 \mathrm{t})$, (5) Sheet rolls and packing $(\mathrm{NC}=$ 1000t), (6) Wax paper $(\mathrm{NC}=1000 \mathrm{t})$, (7) Booklet $(\mathrm{NC}=2600000$ No), (8) Hasp ( $\mathrm{NC}=120000 \mathrm{No}$ ), (9) Decal ( $\mathrm{NC}=6250000$ piece), (10) Multilayer paper bags ( $\mathrm{NC}=12000000 \mathrm{No}),(11)$ Row board (NC=12000 Piece), (12) Wooden and paper disposable products ( $\mathrm{NC}=7565000 \mathrm{t})$, (13) Wooden pencil ( $\mathrm{NC}=324000 \mathrm{No}$ ), (14) Carbon paper $(\mathrm{NC}=450000$ package), (15) Parquet $(\mathrm{NC}=150000$ $\left.\mathrm{m}+150000 \mathrm{~m}^{2}\right),(16)$ Sandpaper $\left(\mathrm{NC}=2000000 \mathrm{~m}^{2}\right)$.

\section{IV.1.6 Iranian Food Manufacturing Industries (IFMPI)}

IFI comprised many of confirmed industries in the industries organization in Iran such as (1) Barley water ( $\mathrm{NC}=30000000$ bottles), (2) Cake and muffins ( $\mathrm{NC}=650 \mathrm{~kg}),(3)$ Canned Beans and Caviar Eggplant ( $\mathrm{NC}=3700 \mathrm{No})$, (4) Canned fish (tuna) $(\mathrm{NC}=11000 \mathrm{No}+1056 \mathrm{t}), \quad$ (5) Canned meat (NC=6500000 bottles), (6) Canned mushrooms ( $\mathrm{NC}=2800000$ bottles), (7) Compote ( $\mathrm{NC}=8000000$ No), (8) Concentrated fructose syrup of corn sugar $(\mathrm{NC}=2400 \mathrm{t}),(9)$ Corn Flakes $(\mathrm{NC}=$ 600t), (10) Fantasy Bread (NC=1000000t), (11) Fish food (NC= $12000 \mathrm{~kg})$, (12) Glucose from starch (NC=2160t), (13) Hamburger $(\mathrm{NC}=1000 \mathrm{t}),(14)$ Margarine $(\mathrm{NC}=12000 \mathrm{t}),(15)$ Milk, yogurt and pasteurized cream (NC=8255t), (16) Date sap $(\mathrm{NC}=2000 \mathrm{t}),(17)$ 
Potatoe based foods ( $\mathrm{NC}=800 \mathrm{t})$, (18) Poultry slaughterhouse (NC=3780000 No), (19) Iodinized salt (NC=10000t), (20) Starch from wheat $(\mathrm{NC}=1580 \mathrm{t})$, (21) Treating fish $(\mathrm{NC}=1000 \mathrm{t}),(22)$ Wafer chocolate $(\mathrm{NC}=500 \mathrm{t}),(23)$ Alcohol from beet molasses $(\mathrm{NC}=1500000 \mathrm{No}),(24)$ Mineral water $(\mathrm{NC}=12000 \mathrm{t}),(25)$ Wheat flour (NC=27000t), (26) Pistachio packaging ( $\mathrm{NC}=1269.5 \mathrm{t}),(27)$ Packing grains; peeling off barley $(\mathrm{NC}=2430 \mathrm{t}),(28)$ Spice Packing $(\mathrm{NC}=250 \mathrm{t}),(29)$ Fruit packaging $(\mathrm{NC}=10000 \mathrm{t}),(30)$ Wafer biscuits $(\mathrm{NC}=1000 \mathrm{t})$, (31) Corn grits $(\mathrm{NC}=5800 \mathrm{t}), \quad(32)$ Biscuit (NC=1000t), (33) Soya protein $(\mathrm{NC}=1900 t)$, (34) Mushroom cultivation $(\mathrm{NC}=600 \mathrm{t}),(35)$ Cheese from fresh milk $(\mathrm{NC}=1500 \mathrm{t})$, (36) Cheese Pizza $(\mathrm{NC}=1500 \mathrm{t})$, (37) Meat and Olive Industrial Powder $(\mathrm{NC}=545.5 \mathrm{t})$, (38) Fish powder $(\mathrm{NC}=500 \mathrm{t})$, (39) Artificial sausage and sausage coating $(\mathrm{NC}=243 \mathrm{t})$, (40) Preparation; packaging of honey ( $\mathrm{NC}=24000 \mathrm{No}),(41)$ Purification and packaging of salt $(\mathrm{NC}=21600 \mathrm{t}),(42)$ Cream dyed $(\mathrm{NC}=1400 \mathrm{t})$, (43) Dates and liquid sugar ( $\mathrm{NC}=4680 \mathrm{t})$, (44) Smoked fish $(\mathrm{NC}=$ $15 \mathrm{t})$, (45) Tomato paste ( $\mathrm{NC}=1500 \mathrm{t})$, (46) Flour string $(\mathrm{NC}=24192$ No), (47) Olive oil (NC=280t), (48) Oil Seeds from Vegetable Seeds (except soya; olive) $(\mathrm{NC}=8000 \mathrm{t}),(49)$ Drying oils $(\mathrm{NC}=$ $1500 t),(50)$ Dried vegetables $(\mathrm{NC}=1412000 \mathrm{No}),(51)$ Soya sauce ( $\mathrm{NC}=60000$ barrels +72000 bottles), (52) Ketchup $(\mathrm{NC}=16000 \mathrm{t})$, (53) Food sauces $(\mathrm{NC}=4451998$ (bottles $300 \mathrm{~g})+1250000$ (bottles $120 \mathrm{~g})$ ), (54) Raisin Packaging ( $\mathrm{NC}=1000 \mathrm{t})$, (55) Dates packaging $(\mathrm{NC}=400 \mathrm{t})$, (56) Sausage $(\mathrm{NC}=1000000 \mathrm{t}),(57)$ Ice $(\mathrm{NC}=12920 \mathrm{t})$.

\section{IV.1.7 Iranian Plastic Industries (IPI)}

Types of IPI based on NC comprised 21 industries such as congressional sheets of PP (Polypropylene) and PS (Polystyrene) (2000 T (Ton)), (1), Flat sheets of PP and PS (1200t), (2), Plastic waste recycling (630t), (3), Plastic buttons (100t), (4), PVC (Polyvinylchloride) hose (500t), (5), Plastic rope (1000t), (6), PVC flooring (1700t), (7), PP bags (900t), (8), Plastic bags (1052.67t), (9), PE (Polyethylene) pipes and fittings (1500t), (10), PVC pipes and joints (1400t), (11), Plastic welding artifacts $(1000000$ No = Number), (12), Plastic bottle (18000 No), (13), PVC shoe bed (2160000 No), (14), Plastic Box (Fruit, Chilli) (246140 No), (15), Plastic flashlight (600000 No), (16), PVC gum (4854109 No), (17), Plastic shaver (75000000 No), (18), Cellular Plastic Sheets (385000 m2), (19), PVC film for agricultural use (21600000 m2), (20), Plastic products (175.26t+13580 rolls), (21).

\section{IV.1.8 Iranian Electronic Products Manufacturing Industries (IEPMI)}

Types of IEPMI based on NC comprised 33 industries such as Flux wire $(\mathrm{NC}=2000 \mathrm{t})(1)$, Thermostat samovar $(\mathrm{NC}=200 \mathrm{~kg})$ (2), Automatic starter ( $\mathrm{NC}=100000 \mathrm{NO}$ ) (3), Automotive starter $(\mathrm{NC}=20000 \mathrm{NO})(4)$, Automatic selector ( $\mathrm{NC}=5400 \mathrm{NO})(5)$, Adapter (NC=100000 NO) (6), Ampere meter, voltmeter ( $\mathrm{NC}=200000 \mathrm{NO}$ ) (7), Alarm ( $\mathrm{NC}=100000 \mathrm{NO})$ (8), Desktop phone device $(\mathrm{NC}=20000 \mathrm{NO})(9)$, Electrical connector $(\mathrm{NC}=5000$ NO) (10), Electro-Motor ( $\mathrm{NC}=120000 \mathrm{NO})$ (11), Electronic thermostat (assembly) ( $\mathrm{NC}=20000 \mathrm{NO}$ ) (12), Electronic laboratory devices $(\mathrm{NC}=10000 \mathrm{NO}) \quad(13)$, Electronic encoder lock $(\mathrm{NC}=100000 \mathrm{NO})(14)$, Electric key and socket $(\mathrm{NC}=500000 \mathrm{NO})$ (15), Soldering iron ( $\mathrm{NC}=110000 \mathrm{NO})(16)$, Sockets and rods $(\mathrm{NC}=2000 \mathrm{NO})$ (17), Flashing device ( $\mathrm{NC}=20000 \mathrm{NO}$ ) (18), Home electric drill ( $\mathrm{NC}=10000 \mathrm{NO}$ ) (19), Household Emergency Light $(\mathrm{NC}=20000 \mathrm{NO})(20)$, Gas torch relay $(\mathrm{NC}=50000 \mathrm{NO})(21)$, Limit Switch (NC=70000 NO) (22), Moonlight ballast $(\mathrm{NC}=200000$ NO) (23), Moonlight Starter ( $\mathrm{NC}=2000000$ NO) (24), Paper loudspeakers ( $\mathrm{NC}=500000 \mathrm{NO}$ ) (25), Projector and spotlight $(\mathrm{NC}=100000 \mathrm{NO})(26)$, Plugs and screws head $(\mathrm{NC}=800000 \mathrm{NO})$
(27), Pocket radio ( $\mathrm{NC}=40000 \mathrm{NO})$ (28), Trans-amplification ( $\mathrm{NC}=100000 \mathrm{NO})(29)$, Trans moonlight $(\mathrm{NC}=450000000 \mathrm{NO})$ (30), Thermal relay ( $\mathrm{NC}=60000 \mathrm{NO})$ (31), Coaxial cables $(\mathrm{NC}=408000$ crank) (32), Electronic boards and printed circuits $\left(\mathrm{NC}=20000 \mathrm{~m}^{2}\right)$ (33). 